\title{
Promoting Science-Based Careers through Student-Directed Learning
}

\author{
Douglas D. McGregor a David R. Fraser
}

\begin{abstract}
Student-directed learning has been featured in a program aimed at promoting the entry of veterinary students into sciencebased careers. Pursuant to that objective, students participated in workshops and role-playing exercises calculated to enhance self-confidence and the development of leadership, teamwork, and communication skills. Insights into research careers and the optimal sequencing of graduate training were also gained through self-study and simulated interviews for research or service positions in industry. The modules were well received by students, who found them enjoyable and relevant to their career aspirations.
\end{abstract}

\section{INTRODUCTION}

The College of Veterinary Medicine (CVM) at Cornell University has hosted an annual Leadership Program since 1990. The program seeks to identify and promote the entry of academically gifted and highly motivated veterinary students into science-based careers. The initiative combines faculty-guided student research, vocational counseling, and group learning experiences in which the students assume a major role in their own education. They do so by participating in career-relevant discussions, workshops, and seminars and by presenting their research findings in an open meeting at the conclusion of the program. Two goals of the program complement the conventional veterinary curriculum. The first is to develop self-confidence, critical thinking, communication, and teamwork skills in the participants and to illustrate the relevance of those skills to careers in science. The second is to empower students to make informed decisions about graduate education and the sequencing of training experiences. Vocational counseling is the principal instrument employed for the latter purpose; however, a module that explores careers in industry is more active, requiring independent study and the participation of students in a role-playing exercise.

This report comments on the structure of the studentdirected events; their evolution over the 16 years that the Leadership Program has been offered; and the perceived value of the exercises in advancing the program's objectives. In particular, it highlights the ways in which student-directed events have evolved to better achieve the program's goals. In addition, the report outlines how the student-directed group exercises have engaged all students and encouraged them to learn and think deeply about the career paths they might follow after earning their veterinary degree.

\section{WORKSHOPS}

The first student-directed event developed for the Leadership Program was structured as a workshop on infectious diseases. The module focuses on diseases that are emerging or re-emerging in nature, often as a consequence of agent mutation, population mobility, habitat destruction, climate change, or the inappropriate use of antibiotics, and on other agents that alter the ecology of microorganisms or vectors of disease. Several models for the workshop were considered, and three were tested. These included mini-lectures by students and faculty and meetings in which one or more facilitators assisted the students in their exploration of individual diseases. Neither model was satisfactory. The lecture format was uninspiring and passive, while the facilitator-guided discussions were dominated by a few students, the others remaining passive and silent. In light of that experience, a third model was devised in which students prepared for the workshop by gathering and assimilating information on the topics to be discussed. They divided themselves into four groups of approximately equal size, and each group chose a disease from a list suggested by expert facilitators. The students conducted library research on the topics they selected, accessed Web-based resources for additional information, and consulted with faculty who were themselves engaged in research on infectious diseases. On the day of the meeting, each group was allocated one hour to present its findings and to engage an audience of students and facilitators in a general discussion.

The student groups often selected a presentation format that was familiar to them. Typically, it was a topic overview in which individuals in the team commented on the causal agent, the pathogenesis of the disease, and its diagnosis and control. While this approach was instructive and helped all the students to learn, presenters devoted excessive time to descriptive aspects of the diseases while neglecting an analysis of the circumstances that lead to disease emergence and strategies for disease control. Moreover, the formality of such presentations provided little opportunity for audience participation.

Over several years this workshop has evolved to a more successful format by encouraging the students to consider presentation techniques other than the lecture and to limit descriptive aspects of their chosen disease to no more than 
10 minutes. Several models have emerged, including interviews, debates, and panel discussions. To promote general discussion, the presenting groups engage their audience in a Socratic dialogue; facilitators intervene only to keep the discussion on track and to raise issues that are insufficiently addressed in the student exchanges.

The presentations span four hours, two in the morning and two in the afternoon. In an evening session, the roles of students and facilitators are reversed. Facilitators take the lead by commenting on their own research and field experiences with infectious diseases. The discussion emphasizes contributions made by veterinary scientists to current knowledge of emerging diseases and the diversity of careers in which veterinary qualified individuals can contribute to the discovery process and disease control.

An additional workshop on infectious diseases was introduced in 2003. This new session extends the theme of spreading infections and explores special problems connected with the deliberate release of pathogenic organisms or their noxious products with the intent of injuring humans or animals (bioterrorism) or causing damage to agricultural systems (agro-terrorism). The format is similar-four one-hour student presentations on individual diseases and an evening session in which the workshop facilitators highlight opportunities for veterinary scientists in infectious disease research and the need for veterinary qualified public-health officers in a comprehensive bio-defense structure.

\section{ROLE-PLAYING EXERCISES}

Role-playing has found a useful place in the education of health professionals. ${ }^{1-5}$ Illustrating life experiences through active participation in a scenario builds self-confidence and the capacity of individuals to communicate effectively. While stressful, especially for less assertive individuals, the experience encourages the development of analytical skills and the ability of students to organize and express their thoughts.

\section{Leadership in Action}

Consideration of the principles of leadership has gradually evolved from question-and-answer discussion sessions to full participation by all students and distinguished guest facilitators in an unprepared and complex roleplaying scenario. The model for this exercise was the US Public Broadcasting System series Ethics in America, which illustrates leadership in action. ${ }^{4}$ Scholars have the opportunity to interact with one another and with experienced facilitators drawn from academic institutions, government, and industry. The students and facilitators are assigned roles, without warning, in a scenario in which they are challenged to deal with veterinary or medical dilemmas complicated by ethical, economic, political, and publicservice considerations. The scenario was deliberately structured to illustrate real-life experiences. ${ }^{6}$ In their assigned roles, the students are obliged to rely on common sense in expressing their opinions on issues that are unfamiliar to them. At the same time, however, they can observe how seasoned scientists, administrators, and leaders in higher education arrive at informed judgments even when their action choices are limited and the outcome uncertain.
The module is a riveting experience. The attention of the protagonists is sustained throughout the three-hour exercise because they are unable to predict when and in what context they will be invited to express an opinion or make a decision. Scholars have exhibited some apprehension in circumstances they cannot anticipate and in which their experience is limited; yet they are enthusiastic and eager to continue the discussion beyond the time scheduled for this event.

The moderator, too, is challenged in keeping the discussion on track. An unscripted scenario involving approximately 30 players often results in spontaneous exchanges between the protagonists and departures from the storyline that the moderator has not anticipated. Deviations of this sort enrich the discussion, but at the same time may constrain the participation of individuals whom the moderator may have intended to engage at a particular point in the proceedings. Nevertheless, the complications are manageable and do not detract from the learning value of the exercise.

\section{Careers in Industry}

Another opportunity to engage Leadership Program scholars in an informative role-playing module serves to acquaint the students with career opportunities for veterinarians in industry. Initial efforts to achieve this objective relied on informal presentations by one or more scientists who were employees of a major pharmaceutical firm. The facilitators commented on a variety of employment positions for which veterinary graduates are desirable or even uniquely qualified candidates; opportunities of this sort were illustrated by the facilitators' own experiences. The guest scientists also described the benefits of an industrial career and drew comparisons between employment in an academic institution and employment in a company where product development and profit are major considerations. The discussions were informative, and provision was made for questions and comments; however, the proceedings were too frequently dominated by the most assertive students and by those who had work experience in an industrial setting.

A role-playing structure offered the prospect of engaging students more broadly while enabling them to develop skills that would serve them well in a search for employment. Several alternatives were considered, but the one selected is structured as an interview. To prepare for the exercise, the students divide themselves into four groups. Each group selects one of four professional job descriptions provided by the facilitators. The résumé of a hypothetical but plausible candidate for each position is also included in a student workbook.

The four groups are interviewed by two facilitators, both senior scientists at Merck Co., a sponsor of the program. The interviews are conducted sequentially so that other students can observe and learn from each interview session. With each group, the facilitators comment on the candidate's responsibilities and on the work environment and employment benefits offered by the company. Thereafter they explore the qualifications and characteristics of the candidate by directing questions in turn to each member of the team. The students are obliged to respond in the context of the individual whose persona they have adopted. As the interviews move toward closure, 
the students are encouraged to raise questions of their own regarding the responsibilities of the position and their prospects for professional advancement.

The module enables students to learn about careers in industry with a clarity comparable to that achieved in earlier programs, in which facilitators dominated the discussion. But the interview format has two additional benefits: first, it engages every student-not just the most assertive; second, it provides practical experience with the interview process. In the course of the meeting, scholars come to appreciate the value of understanding a company's business prior to an interview and the types of questions they should be prepared to answer. The principal limitation is the difficulty of effectively representing a hypothetical candidate whose training and employment history lie outside students' personal experience.

A second student-directed learning module was adapted from an "in-house" training exercise employed by Pfizer Inc., another program sponsor. The "Pfizer module" illustrates strategies and practices underlying the development and marketing of veterinary drugs and biologicals. It also uses role-playing, but in a different context. In this instance, the students distribute themselves into three teams, each representing a company that is attempting to launch a drug for the treatment of osteoarthritis in dogs. The challenge for the mock companies is to develop a safe, effective, and distinctive product. Each team selects a company name and designates group members to serve as directors of discovery, drug safety, formulation and manufacturing, regulatory compliance, technical services, and marketing. Business plans are drafted using a form provided for that purpose. In advance of the meeting, the moderator reviews the three plans and seeks clarification as needed. The moderator highlights problems and requests additional information when ambiguity is a problem or when issues are not adequately addressed.

On the day of the meeting, each group presents a revised plan to the competing student teams, the moderator, and two of her colleagues. The audience challenges the presenting company's strategy and endeavors to steer the discussion in a direction that will favor their own plan. During a 10-minute recess, the three teams meet privately to revise their strategies. Thereafter, they reconvene to defend their business plans and promote their products. The facilitators bring the proceedings to closure by commenting on the strengths and weaknesses of the three business plans and by sharing experiences drawn from their own careers as industrial scientists.

The module is an informative experience. Students enjoy the competitive nature of the exercise and appreciate the insights it provides into employment opportunities for veterinarians in a major research-intensive pharmaceutical firm.

\section{SELF-STUDY}

\section{Participation in Seminars}

Each year, Leadership Program scholars take part in two seminar meetings, one organized by the National Institutes of Health (NIH) and one by the Animal and Natural
Resources Institute of the US Department of Agriculture, both in the Washington, DC, area. Staff scientists of the host institutions describe their research in a series of 30 -minute addresses. The meeting structure is unusual insofar as each presentation is followed by a discussion period of equal length. Scholars prepare for the meetings by conducting library research on at least two of the scheduled seminar topics. They are expected to read a review and at least two original articles on each topic and to ask questions and stimulate discussion following the relevant presentations.

The seminars have been informative and much enjoyed by both the host scientists and their audiences. The meeting structure not only ensures broad student participation but also enables scholars to hone their critical thinking and communication skills.

\section{Career Planning}

A major objective of the Leadership Program is to empower students to make informed decisions about graduate research and post-doctoral training. Critical in this connection is the selection of a mentor. ${ }^{7,8}$ A mentor's influence is especially important early in training, when veterinary graduates often enroll in a graduate program leading to a PhD degree. During this phase of their education, habits are acquired and attitudes toward research are formed that remain with trainees throughout their professional careers.

Experience has shown that the skills needed to function as a successful scientist are frequently passed on from one "generation" to another, although precisely how this transfer is accomplished is subject to debate. Yet many believe that a mentor's role is crucial. An especially persuasive study commissioned by the NIH makes clear that an individual's success in securing an investigatorinitiated NIH research grant is directly related to the training time spent in an intellectually stimulating and creative research environment. ${ }^{9}$

Advising students about mentor selection is a sensitive undertaking, especially when the process involves judging one's colleagues. To avoid this dilemma, the program organizers provide Leadership Program scholars with a "Graduate Studies Planner." This document comments generically on matters relevant to mentor selection and indicates how scholars can access information needed to make informed decisions. Some of the information can be obtained by questioning prospective mentors and individuals currently in training, but additional insights can be gained from information published on the World Wide Web. Scholars are guided to sites that list research support, published results, and the frequency with which an individual's research findings are cited in the scientific literature. Scholars are encouraged to explore these matters on their own initiative.

\section{ASSESSMENT}

Two methods have been used to measure student satisfaction with the Leadership Program and the program's focus on student-directed learning. One was an individual interview with each student; the other sought opinions of the experience through an anonymous questionnaire. 
Interviews have been conducted with every student enrolled in the program from 1998 to 2004. The individual interviews lasted approximately 30 minutes. They explored when, and in what circumstances, students elected to pursue a career in veterinary medicine, their satisfaction with the Leadership Program as a career defining experience, and their thoughts about their research projects and their future. Five to 10 minutes of each interview were recorded on videotape for archival purposes and as part of an ongoing effort to identify factors that influence the career choices made by participating students. In many instances, however, the interviews also elicited comments about the learning modules. The opinions expressed were generally positive and helpful in identifying problems that could be rectified. Prominent among them were the need to specify the objectives of modules and the need to provide guidance in syllabus materials regarding the format of learning experiences, an explanation of the responsibilities of students, and the expected outcome of group exercises.

More information about the group learning experiences was gleaned from the results of a questionnaire completed anonymously by students at the close of the program. In their assessment of five modules, students responded to two questions, one framed as a positive interrogative and one as a negative inquiry. Table 1 reveals a generally high opinion of the exercises. The "Careers in Industry" meeting received a lower score than the other modules, but in this instance assessment was based on the responses of a single "class." The module had not previously been tested; hence, the program organizers had neither the opportunity to refine the exercise based on their own assessment nor the benefit of student suggestions for improving the module.

\section{Table 1: Student assessment of group learning modules (2002-2004)}

\begin{tabular}{llc}
\hline Module & \multicolumn{1}{c}{ Student Response } & Score $^{*}$ \\
\hline Leadership in Action & Valuable learning experience & 4.45 \\
& Not an effective use of my time & 1.41 \\
Emerging Diseases & Valuable learning experience & 4.69 \\
& Not an effective use of my time & 1.38 \\
Biodefense** & Valuable learning experience & 4.70 \\
& Not an effective use of my time & 1.30 \\
Drug Design \& & Valuable learning experience & 4.26 \\
Development & Not an effective use of my time & 1.92 \\
\multirow{2}{*}{ Careers in Industry } & Valuable learning experience & 3.94 \\
& Not an effective use of my time & 1.94 \\
\hline
\end{tabular}

*5 = strong agreement, 1 = strong disagreement.

** Responses of students enrolled in 2003 and 2004.

***Responses of students enrolled in 2004.

\section{DISCUSSION}

The perceived merits of student-directed learning are encapsulated in the following dictum attributed to Confucius:

Tell me and I will forget; show me and I may remember; involve me and I will understand.

Implicit in this statement is the assumption that scholars learn more efficiently from experience, either real or simulated, than from traditional lectures, demonstrations, prescribed syllabus materials, or other forms of passive learning. Although the proposition that experiential learning is a superior method for promoting knowledge retention, creativity, or the development of problem solving skills is intuitively appealing, there is little objective evidence to support it. At the very least, however, it is enjoyable and an effective mechanism for promoting broad student participation.

Experiential learning, especially in group modules, also encourages the development of teamwork and communication skills. In the program described here, students were apprized of the relevance of such skills to leadership and their growing importance to the resolution of problems of global concern to veterinary medicine. It would have been interesting and possibly helpful to supplement the instruction with a formal explanation of group dynamics and the administration of psychological tests designed to illuminate individual personality profiles. However, time constraints prevented any further group exercises.

Video interviews and an anonymous questionnaire completed by Leadership Program scholars at the conclusion of the program revealed gratifying satisfaction with modules that employ role-playing, independent study, group discussions, and presentation of information to an audience composed of scholars and informed facilitators.

The use of student-directed learning tools accords with the proposition that experiential learning has merit in promoting the development of leadership skills and guiding veterinary students into science-based careers. One role-play exercise used in the Leadership Program was especially relevant in that connection: it illustrates leadership in action. Not only does the module ensure broad student participation, it highlights responsibilities incumbent on individuals who are obliged to make decisions under circumstances where there are competing interests and where the pressure of events may require modification of previous positions as events unfold. The scenario is hypothetical, but it is not unlike experiences that confront scientists and public-health officers in the pursuit of their mission to advance knowledge and ensure the health and well-being of humans and animals.

Other modules employed in the Leadership Program require scholars to cooperate and negotiate with one another in the course of their learning and to communicate information, either individually or as members of a team. The requisite skills are relevant to careers of the kind highlighted by the program. Nowhere is that more evident than in the task of protecting animal and human 
populations against diseases that are emerging or re-emerging in nature or of meeting the threat of terrorist acts involving the deliberate release of hazardous agents or their products. Controlling such diseases is a global challenge that requires health professionals to function as members of geographically dispersed problem-solving teams. Student-directed learning fosters that outcome by promoting the development of critical thinking, teamwork, and communication skills.

Cooperation among participating students is also required in a module that addresses practical issues connected with the discovery, development, and marketing of drugs intended for use in animals. These topics are considered infrequently in the typical veterinary curriculum, yet they are important to individuals who contemplate a career in industry. Practical considerations, such as the selection of drug targets, strategies for drug development, and procedures for attaining product approval, are readily addressed in an active learning format. Leadership Program scholars have found this module especially stimulating because it encourages creativity through participation in a mock competition between competing teams.

Self-study is the foundation of student-directed learning and a time-tested method of transferring knowledge. Leadership Program scholars use self-study in preparing for workshops. But this method of learning has found an additional application in encouraging students to participate actively in seminars. Conducting independent research on scheduled seminar topics enables scholars to engage speakers in informed discussions. Such meetings are stimulating and enjoyable. Moreover, they engage all students at some stage in the discussions and, by doing so, enable them to gain confidence and hone their communication skills.

\section{ACKNOWLEDGMENTS}

The Leadership Program is presently funded by grant AE 07227 from the National Institutes of Health and by fellowship awards and grants from Merck and Co., Pfizer Inc., the Albert C. Bostwick Foundation, and the Wellcome Trust. The authors thank Drs. Gerard Hickey and Michelle Haven for their efforts in designing the modules on Careers in Industry and Drug Design and Development, respectively. They also thank Dr. Trevor Heath for his suggestions in constructing the questionnaire used to evaluate the program.

\section{REFERENCES}

1 Mills JN. Use of drama in teaching the human side of veterinary practice. Aust Vet J 75:497-499, 1997.

2 Hardoff D, Schonmann S. Training physicians in communication skills with adolescents using teenage actors as simulated patients. Med Educ 35:188-190, 2001.

3 Knowles C, Kinchington F, Erwin J, Peters B. A randomized control trial of the effectiveness of combining video role play with traditional methods of delivering undergraduate medical education. Sex Transm Infect 77:376-380, 2001.

4 Fraser DR, McGregor DD. An exercise in leadership training for veterinary students aiming for careers in biomedical research. J Vet Med Educ 29:162-166, 2002.

5 Radford AD, Stockley P, Taylor IR, Turner R, Gaskell CJ, Kaney S, Humphries G, Magrath C. Use of simulated clients in training veterinary undergraduates in communication skills. Vet Rec 152:422-427, 2003.

6 Hulton M. Learning from action: a conceptual framework for making sense of experimental learning. In Weil SW, McGill I, eds. Society for Research into Higher Education. Bristol, PA: Open University Press, 1989:50-59.

7 Gywnne P. Success factors for postdocs: ensuring a fruitful fellowship. Science 305:1803-1810, 2004.

8 Making the Right Moves: A Practical Guide to Scientific Management for Postdocs and New Faculty. Research Triangle Park, NC: Burroughs Wellcome Fund and Howard Hughes Medical Institute, 2004 p81-92.

9 Lenfant C. Bomedical Research Training Programs. Bethesda, MD: National Institutes of Health, 1989.

\section{AUTHOR INFORMATION}

Douglas D. McGregor, MD, DPhil, is Professor of Immunology in the College of Veterinary Medicine at Cornell University, Ithaca, NY 14853 USA, and Director of the Cornell Leadership Program for Veterinary Students.

David R. Fraser, PhD, is Professor of Animal Science in the Faculty of Veterinary Science at the University of Sydney, NSW 2006, Australia, and Co-Director of the Leadership Program.

Address correspondence to Dr Douglas McGregor, College of Veterinary Medicine at Cornell University, Ithaca, NY 14853 USA. E-mail: ddm7@cornell.edu. 